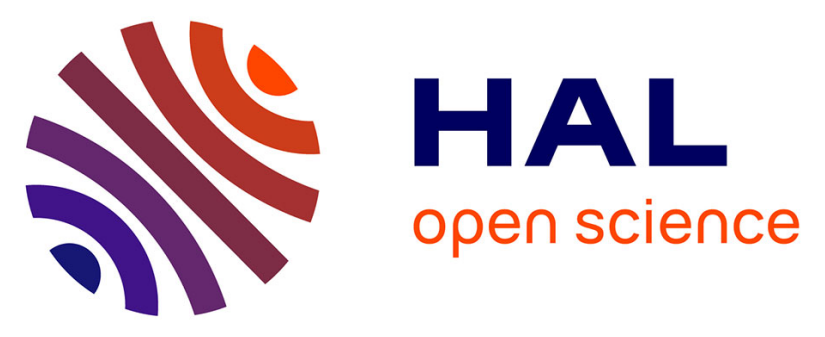

\title{
Once upon a time in the far south: Influence of local drivers and functional traits on plant invasion in the harsh sub-Antarctic islands
}

\author{
Manuele Bazzichetto, François Massol, Marta Carboni, Jonathan Roger \\ Michel Henri Lenoir, Jonas Lembrechts, Rémi Joly, David Renault
}

\section{To cite this version:}

Manuele Bazzichetto, François Massol, Marta Carboni, Jonathan Roger Michel Henri Lenoir, Jonas Lembrechts, et al.. Once upon a time in the far south: Influence of local drivers and functional traits on plant invasion in the harsh sub-Antarctic islands. Journal of Vegetation Science, 2021, 32 (4), pp.e13057. 10.1111/jvs.13057 . hal-03362958

\section{HAL Id: hal-03362958 \\ https://hal.science/hal-03362958}

Submitted on 2 Oct 2021

HAL is a multi-disciplinary open access archive for the deposit and dissemination of scientific research documents, whether they are published or not. The documents may come from teaching and research institutions in France or abroad, or from public or private research centers.
L'archive ouverte pluridisciplinaire HAL, est destinée au dépôt et à la diffusion de documents scientifiques de niveau recherche, publiés ou non, émanant des établissements d'enseignement et de recherche français ou étrangers, des laboratoires publics ou privés. 


\section{Title page}

\section{Once upon a time in the far south: Influence of local drivers and functional traits on plant invasion in the harsh sub-Antarctic islands}

Bazzichetto $^{1 *}$, M., Massol${ }^{2}$, F., Carboni ${ }^{3}$, M., Lenoir ${ }^{4}$, J., Lembrechts ${ }^{5}$, J. J., Joly ${ }^{1}$, R., \& Renault ${ }^{1,6}$, D.

${ }^{1}$ Université de Rennes, CNRS, EcoBio (Ecosystèmes, biodiversité, évolution) - UMR 6553, F-35000 Rennes, France

${ }^{2}$ Université de Lille, CNRS, Inserm, CHU Lille, Institut Pasteur de Lille, U1019 - UMR 9017 - CIIL - Center for Infection and Immunity of Lille, F-59000 Lille, France

${ }^{3}$ Department of Sciences, University Roma Tre, Rome, Italy

${ }^{4}$ UR 'Ecologie et Dynamique des Systèmes Anthropisés' (EDYSAN, UMR 7058 CNRS-UPJV), Université de Picardie Jules Verne, Amiens, France

${ }^{5}$ Research Group PLECO (Plants and Ecosystems), University of Antwerp, 2610 Wilrijk, Belgium

${ }^{6}$ Institut Universitaire de France, 1 rue Descartes, 75231 Paris Cedex 05, France

*corresponding author

\section{Authors information:}

Massol François: Univ. Lille, CNRS, Inserm, CHU Lille, Institut Pasteur de Lille, U1019 - UMR 9017 - CIIL - Center for Infection and Immunity of Lille, F-59000 Lille, France

francois.massol@univ-lille.fr

ORCID: https://orcid.org/0000-0002-4098-955X

Carboni Marta: Department of Sciences, University Roma Tre, Rome, Italy marta.carboni@uniroma3.it

ORCID: https://orcid.org/0000-0002-9348-4758

Lenoir Jonathan: UR 'Ecologie et Dynamique des Systèmes Anthropisés' (EDYSAN, UMR 7058 CNRS-UPJV), Université de Picardie Jules Verne, Amiens, France

jonathan.lenoir@u-picardie.fr

ORCID: https://orcid.org/0000-0003-0638-9582

Lembrechts Jonas Johan: Research Group PLECO (Plants and Ecosystems), University of Antwerp, 2610 Wilrijk, Belgium

jonas.lembrechts@uantwerpen.be

ORCID: https://orcid.org/0000-0002-1933-0750 
Joly Rémi: Université de Rennes, CNRS, EcoBio (Ecosystèmes, biodiversité, évolution) - UMR 6553, F-35000 Rennes, France

remi.joly88@hotmail.fr

Renault David: Université de Rennes, CNRS, EcoBio (Ecosystèmes, biodiversité, évolution) - UMR 6553, F-35000 Rennes, France; Institut Universitaire de France (IUF), 1 rue Descartes, 75231 Paris Cedex 05, France

david.renault@univ-rennes1.fr

ORCID: https://orcid.org/0000-0003-3644-1759

Bazzichetto Manuele (corresponding author): Université de Rennes, CNRS, EcoBio (Ecosystèmes, biodiversité, évolution) - UMR 6553, F-35000 Rennes, France

manuele.bazzichetto@univ-rennes1.fr

ORCID: https://orcid.org/0000-0002-9874-5064 


\title{
Once upon a time in the far south: Influence of local drivers and functional traits on plant invasion in the harsh sub-Antarctic islands
}

\author{
Manuele Bazzichetto ${ }^{1 *}$, François Massol$^{2}$, Marta Carboni ${ }^{3}$, Jonathan Lenoir ${ }^{4}$, Jonas J Lembrechts ${ }^{5}$, \\ Rémi Joly ${ }^{1}, \&$ David Renault ${ }^{1,6}$ \\ ${ }^{1}$ Université de Rennes, CNRS, EcoBio (Ecosystèmes, biodiversité, évolution) - UMR 6553, F-35000 Rennes, France \\ ${ }^{2}$ Université de Lille, CNRS, Inserm, CHU Lille, Institut Pasteur de Lille, U1019 - UMR 9017 - CIIL - Center for Infection \\ and Immunity of Lille, F-59000 Lille, France \\ ${ }^{3}$ Department of Sciences, University Roma Tre, Rome, Italy \\ ${ }^{4}$ UR ‘Ecologie et Dynamique des Systèmes Anthropisés’ (EDYSAN, UMR 7058 CNRS-UPJV), Université de Picardie \\ Jules Verne, Amiens, France \\ ${ }^{5}$ Research Group PLECO (Plants and Ecosystems), University of Antwerp, 2610 Wilrijk, Belgium \\ ${ }^{6}$ Institut Universitaire de France, 1 rue Descartes, 75231 Paris Cedex 05, France \\ *corresponding author
}

\section{Abstract}

Aim

Here, we aim to: (i) investigate the local effect of environmental and human-related factors on alien plant invasion in sub-Antarctic islands; (ii) explore the relationship between alien species features and their dependence on anthropogenic propagule pressure; and (iii) unravel key traits conferring invasiveness in the sub-Antarctic.

\section{Location}

Possession Island, Crozet archipelago (French sub-Antarctic islands).

\section{Taxon}

Non-native vascular plants (Poaceae, Caryophyllaceae, Juncaceae).

\section{Methods}

Single-species distribution models were used to explore the effect of high-resolution topoclimatic and human-related variables on the occurrence of six of the most aggressive alien plants colonizing French sub-Antarctic islands. Furthermore, the interaction between alien species traits and their response to anthropogenic propagule pressure was analysed by means of a multi-species distribution model. This allowed identifying the features of species that were associated to low dependence on human-assisted introductions, and were thus potentially more invasive.

\section{Results}

We observed two main invasion patterns: low-spread species strongly dependent on anthropogenic propagule pressure and high-spread species limited mainly by harsh climatic conditions. Differences in invasiveness across species mostly related to their residence time, life history and plant height, with older introductions, perennial and low-stature species being more invasive. 
24 The availability of high-resolution data improved our understanding of the role of environmental and 25 human-related factors in driving alien species distribution on sub-Antarctic islands. At the same time, 26 the identification of alien species features conferring invasiveness may help anticipating future 27 problematic invasions.

Keywords: alien plants, anthropogenic propagule pressure, invasiveness, plant invasion, species distribution models, sub-Antarctic islands, topoclimate 


\section{Introduction}

Sub-Antarctic islands, archipelagos scattered within the $54-48^{\circ} \mathrm{S}$ latitudinal ring, are extremely remote territories which harbour a unique biodiversity with a high degree of endemism (Shaw, 2013). As a consequence of their relatively recent discovery and environmental harshness, these islands have long remained pristine and largely free of human disturbances. Yet, due to the gradual relaxation of these natural barriers, sub-Antarctic islands are now listed among the most threatened environments on Earth. In particular, invasion by alien plants, boosted by ongoing climate changes and increasing human disturbances (Duffy \& Lee, 2019; Hughes et al., 2019), has become one of the main threats to the endemic biodiversity of these territories, and is bound to rise in the next decades (Lebouvier et al., 2011; Hughes, Pertierra, Molina-Montenegro, \& Convey, 2015). Over the past century, alien plants have been increasingly introduced in the sub-Antarctic region (Frenot et al., 2005; Huiskes et al., 2014). European whalers and scientific activities, respectively in the $19^{\text {th }}$ and $20^{\text {th }}$ century, determined the first main introduction events (Convey \& Lebouvier, 2009; Shaw, 2013). Later on and since the mid-twentieth century, climate warming, strong changes in precipitation regimes and the widespread impacts of non-native vertebrates have progressively favoured the establishment of coldtolerant alien plants on sub-Antarctic islands (Shaw, 2013; Pertierra et al., 2017; Duffy \& Lee, 2019). Nevertheless, despite their demonstrated impacts on native biodiversity, little attention has been given to plant invasions compared to animal invasions on these islands (le Roux et al., 2013), leaving a knowledge gap in the mechanisms underpinning plant invasion processes in these unique environments (Greve, Mathakutha, Steyn, \& Chown, 2017).

The outcome of any biological invasion is jointly determined by propagule pressure (i.e. frequency of propagules introduction), abiotic conditions (i.e. physico-chemical features of the invaded environment) and biotic features (i.e. alien species characteristics and interactions with the recipient community), with anthropogenic disturbances affecting all three (Richardson \& Pyšek, 2006; Catford, Jansson, \& Nilsson, 2009; Lembrechts et al., 2016). The relative importance of these factors is, however, context-dependent and species-specific (Catford et al., 2009). In sub-Antarctic islands, due to the high specialization but low diversity of the native flora, biotic interactions are thought to play a minor role (le Roux et al., 2013; Duffy et al., 2017; Moser et al., 2018), so it is mainly the first two factors that determine the distribution and spread of alien plants. First, invasions depend on humaninduced propagule pressure: the frequency of propagule introduction correlates with the number of ship landings and is highest in the vicinity of human facilities (Huiskes et al., 2014). Second, local abiotic conditions are strongly limiting, and particularly the climatic mismatch between the conditions prevailing within the alien species' native range and the conditions prevailing in the sub-Antarctic can strongly constrain invasions (Frenot et al., 2005). Some alien plants are more limited during the introduction phase, while others quickly become relatively independent of human-related propagulepressure and seem only climatically limited. Once established, the species which are the least dependent on continuous introductions are the most likely to spread widely and become invasive (Richardson \& Pyšek, 2006; Catford et al., 2009). Therefore, quantifying the degree of alien species dependence on propagule pressure might aid at identifying potentially invasive species.

A lower dependence on human-related propagule pressure is potentially related to certain species features which are more generally known to affect invasiveness. First of all, alien species with longer residence times are more likely to become independent of anthropogenic propagule pressure (Wilson et al., 2007; Pyšek et al., 2015). Second, certain plant traits are considered key for profiling successful invaders (Pyšek \& Richardson, 2008): invasive alien plants across most environments are growing faster and taller than non-invasive alien species, and typically produce resource-acquisitive leaves and many small seeds (van Kleunen, Weber, \& Fischer, 2010; van Kleunen, Dawson, \& Maurel, 
2015). More specifically, Mathakutha et al. (2019) performed a first functional comparison between invasive and non-invasive alien species colonizing the sub-Antarctic Marion Island, reporting that species generally considered invasive had lower plant height, smaller leaf area, lower frost tolerance and higher specific leaf area than other alien species. Nevertheless, it is still unclear which traits can actually make some alien plants less dependent on human-related propagule pressure, and thus more likely to become invasive, especially in the sub-Antarctic islands. This knowledge could facilitate the early screening of highly invasive alien plant species in these environments (Frenot et al., 2005; Mathakutha et al., 2019).

Correlative species distribution models (SDMs) are statistical tools that model the speciesenvironment relationship relying on geo-referenced occurrence data and spatial environmental layers (Guisan, Thuiller, \& Zimmermann, 2017). Such models already proved to be valuable tools for analysing alien plant invasion in Antarctica and the sub-Antarctic regions. For instance, Pertierra et al. (2017) modelled the distribution of Poa annua and Poa pratensis in the Antarctic peninsula as a function of bioclimatic variables, while Duffy et al. (2017) generated future scenarios of invasion across Antarctica and the sub-Antarctic regions using climate-based SDMs. Whilst these previous SDM applications have revealed large-scale determinants of alien plant invasion in the Antarctic biogeographic region, they have up till now failed to account for how environmental and anthropogenic factors regulate alien plant distributions at a spatial resolution that is meaningful for local management. This is chiefly due to the lack of high-resolution environmental (e.g. climatic, topographic) and human-related data layers, which limits the implementation of SDMs at fine spatial resolutions in remote areas (Gutt et al., 2012). A more general limitation inherent to the use of SDMs for modelling biological invasion is that SDMs allow mapping into the geographical space only a snapshot of the current alien species-environment relationship net of dispersal and biotic constraints (i.e. realized distribution), while necessarily underestimating the actual area potentially suitable to a species for establishing and maintaining a viable population (i.e. potential distribution; see JiménezValverde et al., 2011 and Srivastava, Lafond, \& Griess, 2019).

The sub-Antarctic Possession Island constitutes an ideal arena to analyse alien plant invasions in the sub-Antarctic region. The availability of historical vegetation observations allows retracing the invasion history of most alien plant species on the island. Moreover, this island witnessed past human colonization and climate changes comparable to the other sub-Antarctic islands, allowing inference on the mechanisms underpinning alien plant invasion in these unique areas. Previous work showed that there is considerable variation in the spread of alien plants established on Possession Island, with some species clustering close to their introduction locations and others spreading widely and far from the initial introduction sites (Frenot et al., 2005), which allows testing for differences in the dependence on human introductions. In the present study, we model the distribution of the most relevant alien plant species colonizing Possession Island using a combination of environmental and human-related spatial data derived at an unprecedented high spatial resolution (i.e. 30-m) for these latitudes that we related to long-term monitoring observations of plant occurrences. Our aim is to test the local effect of environmental and anthropogenic factors on alien plant invasion in sub-Antarctic ecosystems. We hypothesise that both abiotic and human-related factors jointly define the local occurrence of alien plant species, but that these two factors will not be equally important among species. Furthermore, to identify plant characteristics conferring high invasiveness in sub-Antarctic ecosystems, we investigate how plant functional traits affect species dependence on anthropogenic propagule pressures. In this regard, our working hypothesis is that the most invasive species share specific functional characteristics allowing them to become independent of human-assisted introductions and spread widely once established. 


\subsection{Study area}

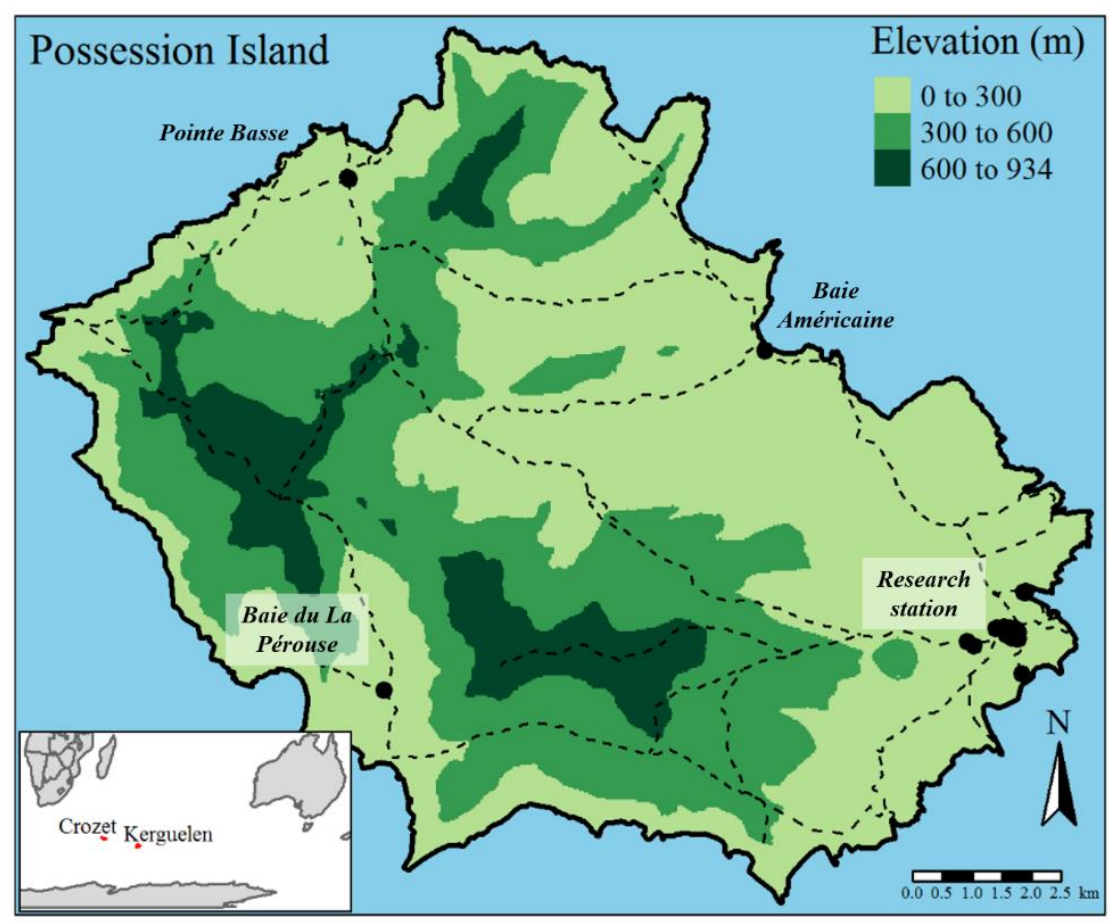

Figure 1-Map of Possession Island showing: gross topography using three altitudinal belts $(0-300 \mathrm{~m} ; 300-600 \mathrm{~m}$; 600-

The study was carried out on Possession Island in the Crozet archipelago, which is included in the Réserve naturelle nationale des terres australes françaises (RNN TAF) and listed as UNESCO World Heritage site since 2019. Possession Island (Figure 1) is characterized by a complex topography, with an altitudinal gradient ranging from 0 to $934 \mathrm{~m}$ above the sea level (Pic du Mascarin) over a relatively short spatial extent $\left(147 \mathrm{~km}^{2}\right)$. The island is characterized by a typical sub-Antarctic climate, with mean annual temperature of $5.6^{\circ} \mathrm{C}$ and annual precipitation of 2,300 $\mathrm{mm}$ (Météo France, data: 19602019). Frequent and strong western winds occur throughout most of the year.

139

The first human settlements date back to the $19^{\text {th }}$ century, when whalers and sealers established on the north-east side of the island during the hunting season, facilitating a first series of alien species introductions. In 1963, a permanent research station (Alfred Faure, hereafter the 'research station') was built on the easternmost area of Possession Island, fostering a new invasion front. Beyond the research station, other shelters (inhabited for short periods) are currently present on each side of the island: north (Pointe Basse); south-west (Baie du La Pérouse); and north-east (Baie Américaine). Among these, the research station is by far the biggest human settlement and main hub of propagule introduction. The vegetation at Possession Island has experienced relatively low grazing pressure from sheep in the past (Convey \& Lebouvier, 2009), in comparison to other sub-Antarctic islands where introduced large herbivores still strongly affect the distribution of alien plants (Shaw, 2013).

\subsection{Study species}

Despite the 68 alien species recorded on Possession Island (see page 99 of the RNN TAF management plan 2018-2027: https://taaf.fr//content/uploads/sites/2/2019/09/180607-Volet-A_pour-CNPN.pdf), 
only few have established persistent populations (Frenot, Gloaguen, Massé, \& Lebouvier, 2001). In this study, we restricted our analysis to those alien plants that are either known to be generally widespread on sub-Antarctic islands or are particularly widespread on Possession Island, and for which sufficient occurrence data were available (total number of presences $>100$ ). Specifically, we selected the following six species from three different families: Poa annua and Poa pratensis (Poaceae); Cerastium fontanum, Sagina procumbens and Stellaria alsine (Caryophyllaceae); and Juncus bufonius (Juncaceae). The two grasses, $P$. annua and $P$. pratensis, have colonised most of the sub-Antarctic islands (Shaw, 2013) and are the longest-established alien plants in the Antarctic Peninsula (Pertierra et al., 2017). Cerastium fontanum and S. procumbens are currently widely distributed in this environment (Frenot et al., 2005; Shaw, 2013) with, in particular, S. procumbens exhibiting the highest rate of spread among the alien plants of Marion and Prince Edward Islands (le Roux et al., 2013). Finally, both J. bufonius and S. alsine currently occur at significant distances from the research station on Possession Island (Frenot el al., 2001). While the former has been recently observed up to the Maritime Antarctica latitudes (Cuba-Díaz, Fuentes, \& Rondanelli-Reyes, 2015), the latter has been singled out by some authors as the potentially most problematic future invasive plant species on Possession Island (Frenot et al., 2001; Convey, Key, \& Key, 2010).

\subsubsection{Species distribution data}

We analysed the invasion patterns of the six selected alien plant species relying on georeferenced occurrence (presence/absence) data collected within the context of a yearly vegetation monitoring survey carried out by the RNN TAF since 2010. The vegetation sampling is implemented within a system of 675 squared cells of $100 \times 100 \mathrm{~m}$ each, where floristic data (presence and abundance of vascular plant species) are collected along with habitat characteristics through phytosociological relevés (Dengler, 2016). In this study, we used data collected from 2010 to 2017 (3,354 occurrences for the selected species across 1,572 sampled plots).

\subsubsection{Species features and functional trait data}

To inform species features (e.g. traits) potentially related to invasiveness, we collected data on plants residence time and functional traits. Residence time positively interacts with propagule pressure in determining plant invasion success (Richardson \& Pyšek, 2006; Lockwood, Cassey, \& Blackburn, 2005; Pyšek et al., 2015), and this relationship was also observed on sub-Antarctic islands (le Roux et al., 2013; Shaw, 2013; Mathakutha et al., 2019). To test how residence time influences alien species' dependence on propagule pressure, we considered the introduction date of the selected plants on Possession Island (Frenot et al., 2001) and used this information to assign them to two groups: old vs new resident species (Appendix S1, Table S1.1). In particular, we considered as old resident species those which were firstly observed on Possession Island before the research station was built (1963), while referring to the others as new resident species.

We then collated data on seven plant traits commonly used to synthesize species strategies known to be related to invasiveness (van Kleunen et al., 2010; van Kleunen et al., 2015): (1) life history (annual vs perennial); (2) plant height; (3) leaf area; (4) specific leaf area (SLA); (5) vegetative reproduction (present $v s$ absent, i.e. sexual and vegetative $v s$ only sexual reproduction); (6) seed dry mass; and (7) number of seeds per plant. We excluded traits related to flowering since pollinating insects are absent from almost all sub-Antarctic islands (Convey et al., 2010). Life history, plant height and leaf area relate to plant persistence and tolerance to environmental stress (Cornelissen et al., 2003; PérezHarguindeguy et al., 2013). In addition, life history is used to assess maximum lifespan and plant height is associated with competitiveness for light and whole plant fecundity (Pérez-Harguindeguy et al., 2013). Specific leaf area is the one-sided leaf area per leaf mass and is associated with resource 
acquisition and photosynthetic rate (Pérez-Harguindeguy et al., 2013). Reproduction strategy, seed dry mass and number of seeds per plant do not only relate with species persistence, but also with dispersal capacity (Ottaviani et al., 2020). In particular, alien species reproducing predominantly sexually may benefit from lower dispersal limitation and greater genetic diversity (van Kleunen et al., 2015). At the same time, while small and light seeds are better dispersed at longer distances, largeseeded plants may benefit from more stored resources (van Kleunen et al., 2015).

Functional trait data collected in areas environmentally analogous to Possession Island were compiled from the literature (other sub-Antarctic islands, Frenot et al., 2005; Marion Island, Mathakutha et al., 2019). Whenever we could not find information collected in comparable environments, we relied on functional trait data included in the TRY database (Kattge et al., 2020). For each alien species, the dominant reproduction strategy in the study area was assessed relying on expert-based knowledge (personal communication, Lebouvier, M., \& Bittebiere, A.K.). Species-specific values of the functional traits are reported in table S1.1 (Appendix S1) along with literature sources.

\subsection{Topoclimatic layers}

To model the species-environment relationship at fine spatial resolution, we first downloaded coarsegrained temperature (BIO1, BIO5 and BIO6 - annual mean temperature, max temperature of the warmest month and min temperature of the coldest month) and annual precipitation (BIO12) grid layers at 1-km resolution (at the equator) from the CHELSA database (Karger et al., 2017) and then disaggregated their spatial resolution using physiographically informed models fitted through geographically weighted regression (GWR; Fotheringham \& Rogerson, 2008). This downscaling technique allows statistically predicting the local value of the coarse-grain CHELSA climatic variables as a function of environmental grid layers available at finer spatial resolution (in this study 30-m at the equator, hereafter 30-m) and known to drive microclimate heterogeneity (Lenoir, Hattab, \& Pierre, 2017; Lembrechts et al., 2019). GWR-derived topoclimatic layers, beyond allowing to model the species-environment relationship at a more meaningful spatial resolution, have already proved to better account for the complex interactions between macroclimate and topography (Lenoir et al., 2017; Lembrechts et al., 2019).

As using BIO5 (max temperature of the warmest month) and BIO6 (min temperature of the coldest month) in place of BIO1 did not improve species distribution models, we ultimately used BIO1 (hereafter mean temperature) and BIO12 as topoclimatic predictors. A full description of the downscaling procedure is reported in Appendix S2 along with the results of the GWR models.

\subsection{Human-related layers}

As human disturbances are known to favour the establishment of alien plants through propagule introduction and alteration of habitat conditions, we generated a 30-m resolution layer reporting the distance between each human settlement (the research station, Baie du La Pérouse, Pointe Basse and Baie Américaine) and any location on the island. Specifically, assuming that human disturbance is stronger in more accessible areas, we derived a least cost distance grid layer providing a measure of accessibility. Terrain slope changes between both orthogonally and diagonally neighbouring raster cells were used to compute the cost of reaching any location on Possession Island starting from any human settlement and following all potential paths of raster cells (function "accCost", "gdistance" R package; Etten, 2018). High costs were thus associated with locations not easily reachable from human settlements due to high topographic roughness (Appendix S3, Figure S3.2).

A network of hiking paths has been designed by RNN TAF to restrict human movements for wildlife conservation purposes, and walking these paths currently constitutes the only authorized way to move 
across the island. As humans are a critical vector of propagule introduction and dispersal on subAntarctic islands, we derived a 30-m resolution raster layer reporting the distance between any location on Possession Island and the closest hiking path using the function "distance" from the "raster" R package (Hijmans, 2019) (Appendix S3, Figure S3.2).

\subsection{Alien species distribution modelling}

The occurrence probability of the six studied alien plant species was separately modelled as a function of the topoclimatic (mean temperature and annual precipitation) and human-related variables (path distance and least cost) by means of logit binary generalized linear models (GLM). The single-species distribution models (single-SDMs) were trained and tested on datasets obtained through a re-sampling procedure of the presence/absence data performed in the environmental space to reflect all available environmental conditions on Possession Island (Lenoir et al., 2010; Hattab et al., 2017; see Appendix S4). All four topoclimatic and human-related predictors were retained to fit the single-SDMs as the relative variance inflation factor (function "vif", R package "car"; Fox \& Weisberg, 2019) was always below a threshold of 3. Second-order polynomial terms were included in the model to allow for intermediate niche optima of the species or in case lack-of-fit tests detected consistent departure from linearity in the profile of Pearson residuals (function "residualPlots", R package "car"; Fox \& Weisberg, 2019). The statistical significance of each predictor was tested using type II analysis of deviance (function "Anova", R package "car"; Fox \& Weisberg, 2019). We then computed the likelihood profile-based $95 \%$ confidence intervals of the regression parameters.

Single-SDMs predictive performance was measured using the true skill statistic (TSS, equal to sensitivity + specificity - 1; function "ecospat.max.tss", R package "ecospat"; Broennimann, Di Cola, \& Guisan, 2018) computed on the testing datasets obtained through the environmental matching described in Appendix S4. We used the TSS as it has desirable properties of other accuracy measures (e.g. Kappa and AUC), while being unaffected by prevalence (Allouche, Tsoar, \& Kadmon, 2006). Also, we computed the deviance-based $\mathrm{R}^{2}$ value as a measure of goodness-of-fit of each single-SDM.

The occurrence probability estimated by the full single-SDMs (including both topoclimatic and human-related predictors) for each alien plant species was mapped on a 30-m raster grid layer to visualise their predicted distribution across Possession Island.

\subsection{Relationship between plant traits and alien species dependence on propagule pressure}

As preliminary analyses, we measured the relative importance of human-related variables in determining alien species occurrence in the single-SDMs. To this aim, we used the sum of Akaike weights $(w)$, which provides an easily interpretable measure of variable importance (it ranges from 0 to 1 , with a high value for a given variable indicating its high importance relative to the others; Burnham \& Anderson, 2002). Then we graphically related the species-specific values of the functional traits to the sum of weights to look for relationships between plant traits and the importance of human-related variables (see Appendix S7).

Secondly, we investigated how the interaction between human-related variables and plant traits affected alien species occurrence in a multi-species distribution model (multi-SDM), focusing on those functional traits that showed some relationship with the dependence on human-related variables in the single-SDMs. To this aim, we modelled the occurrence of all alien species together as a function of topoclimatic and human-related variables by means of a logit binary GLM, including the interaction between species identity and topoclimatic variables on the one hand and the interaction between species functional traits and human-related variables on the other hand. This allowed exploring how the effect of human-related variables on alien species occurrence varied according to 
plant traits, while controlling for species-specific responses to topoclimate. To select the most parsimonious model, we fitted all possible sub-models including different combinations of the functional traits-anthropogenic variables interaction terms (function "dredge", R package "MuMIn"; Barton, 2019), always retaining the species-topoclimate interaction terms and the main effect of path distance and least cost in each candidate sub-model. Then, we computed the sum of Akaike weights for each model term and used the evidence ratio as a measure of the relative importance of variables (Massol et al., 2007; Burnham \& Anderson, 2002). Specifically, we computed the evidence ratio of the $i$-th variable $\left(E R_{i}\right)$ as the odds of its sum of Akaike weights:

$$
E R i=\frac{W i}{1-W i}
$$

The evidence ratio was then compared with its expected value $\left(E R_{\text {null }}\right)$ under the "null hypothesis" that the variable explained as much deviance as a randomly generated explanatory variable, and would thus be as likely as not to be incorporated in the best models. As all the variables were tested in a balanced design, $E R_{\text {null }}=1$ in all tested cases. Following Massol et al. (2007), the effect of a variable $i$ was deemed unlikely if $E R_{i}<0.37 \times E R_{\text {null }}$, implausible when $0.37 \times E R_{\text {null }}<E R_{i}<E R_{\text {null }}$, plausible when $E R_{\text {null }}<E R_{i}<2.72 \times E R_{\text {null }}$, and likely when $E R_{i}>2.72 \times E R_{\text {null }}$. These thresholds correspond to differences in Akaike information criterion equal to +2 or -2 , which are commonly admitted as a good rule-of-thumb gap to compare model performance.

\section{Results}

\subsection{Effect of topoclimatic and human-related variables on single species distribution}

Predictive performances of the single-SDMs varied greatly across species (Table 1): high values of TSS were observed for $P$. pratensis, $S$. alsine and $J$. bufonius (0.80-0.82), while low values were obtained for the remaining species (from 0.09 to 0.29 ). The $\mathrm{R}^{2}$ values showed a similar trend, with the highest value obtained for J. bufonius (0.48) and the lowest for C. fontanum (0.02).

Overall, the occurrence of $P$. pratensis, S. alsine and J. bufonius appeared to be strongly conditioned by both topoclimatic and human-related variables, while $C$. fontanum, $P$. annua and $S$. procumbens were less affected by human-related variables (Table 1, Figures 2 and 3 ).

All alien species, except $S$. alsine, exhibited a significant positive or humped-shaped relationship with mean temperature (Table 1), meaning that their occurrence probability increased with increasing temperature (Figure 2, Appendix S5). More specifically, the occurrence probability of J. bufonius, $S$. procumbens and $C$. fontanum peaked at mean temperature values around $4.5^{\circ} \mathrm{C}$, while the presence of $P$. pratensis and $P$. annua increased more or less linearly with temperature.

Annual precipitation significantly affected the presence of $P$. pratensis, S. alsine and J. bufonius, while it had a minor influence on the occurrence of the other species (Table 1). In particular, the odds of finding P. pratensis and J. bufonius decreased approximately by $90 \%$ for each $500 \mathrm{~mm}$ increment in annual precipitation, while the occurrence probability of $S$. alsine sharply decreased for annual precipitation values above 1,500 $\mathrm{mm}$ (Figure 2).

All species except $C$. fontanum exhibited a significant negative relationship with path distance (i.e. the occurrence probability of the species decreased at increasing distances from the hiking paths), though its influence varied among species (Table 1, Figure 2, Appendix S5). In this regard, the odds of finding P. pratensis, S. alsine and J. bufonius decreased respectively by $20 \%, 16 \%$ and $19 \%$ moving $100 \mathrm{~m}$ away from the paths, while the odds of finding $P$. annua and S. procumbens decreased by $4 \%$ and $6 \%$, respectively. 
327 Least cost distance to settlements appeared to influence the occurrence of all analysed species except 328 S. procumbens (Table 1). In particular, the odds of finding P. pratensis, S. alsine and J. bufonius 329 decreased, respectively, by $17 \%, 13 \%$ and $44 \%$ for each increment of 5,000 units of cost of travelling 330 a given path from a human settlement (Figure 2, Appendix S5). On the contrary, $C$. fontanum and $P$. 331 апnиа showed a positive relationship with least cost, with their odds of occurring increasing 332 respectively by $9 \%$ and $5 \%$ for each increment of 5,000 units of cost of travelling a given path from 333 a human settlement (Figure 2 and Appendix S5). 
bioRxiv preprint doi: https://doi.org/10.1101/2020 07.19 210880; this version posted November 24, 2020. The copyright holder for this preprint (which was not certified by peer review) is the author/funder. All rights reserved. No reuse allowed without permission.
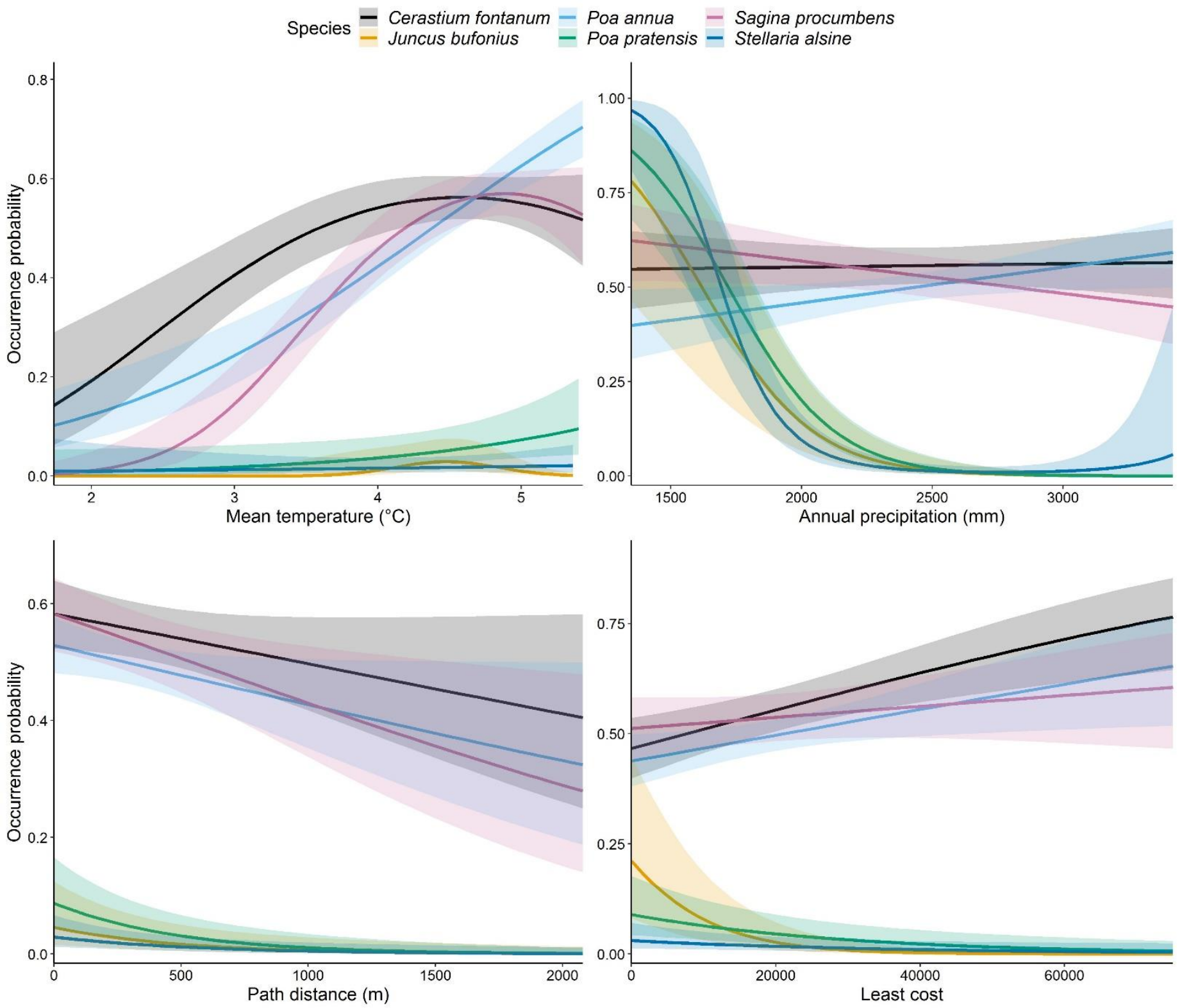

Figure 2 - Response curves of the analysed alien species in the single-SDMs. 


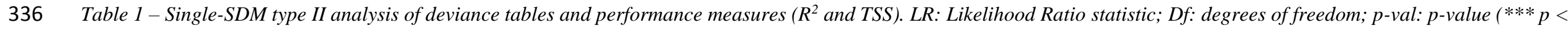
$3370.001 ; * * p<0.01 ; * p<0.05$ ).

\begin{tabular}{|c|c|c|c|c|c|c|c|c|c|c|c|c|c|c|c|c|c|c|}
\hline \multirow[b]{2}{*}{ Predictors } & \multicolumn{3}{|c|}{ Poa pratensis } & \multicolumn{3}{|c|}{ Juncus bufonius } & \multicolumn{3}{|c|}{ Stellaria alsine } & \multicolumn{3}{|c|}{ Poa annua } & \multicolumn{3}{|c|}{ Sagina procumbens } & \multicolumn{3}{|c|}{ Cerastium fontanum } \\
\hline & LR & Df & p-val & LR & Df & p-val & LR & Df & p-val & LR & Df & p-val & LR & Df & p-val & LR & Df & $\mathrm{p}$-val \\
\hline Mean temperature & 5.083 & 1 & $*$ & 32.516 & 2 & $* * *$ & 0.312 & 1 & $=0.576$ & 55.538 & 1 & $* * *$ & 62.554 & 2 & $* * *$ & 18.325 & 2 & $* * *$ \\
\hline Annual precipitation & 106.443 & 1 & $* * *$ & 73.647 & 1 & $* * *$ & 68.406 & 2 & $* * *$ & 4.759 & 1 & $*$ & 3.681 & 1 & $=0.055$ & 0.041 & 1 & $=0.840$ \\
\hline Least cost & 10.837 & 1 & $* * *$ & 40.250 & 1 & $* * *$ & 4.420 & 1 & $*$ & 5.778 & 1 & $*$ & 1.118 & 1 & $=0.290$ & 12.483 & 1 & $* * *$ \\
\hline $\mathbf{R}^{2}$ & & & 0.46 & & & 0.48 & & & 0.36 & & & 0.06 & & & 0.10 & & & 0.02 \\
\hline TSS & & & 0.80 & & & 0.81 & & & 0.82 & & & 0.19 & & & 0.29 & & & 0.09 \\
\hline
\end{tabular}



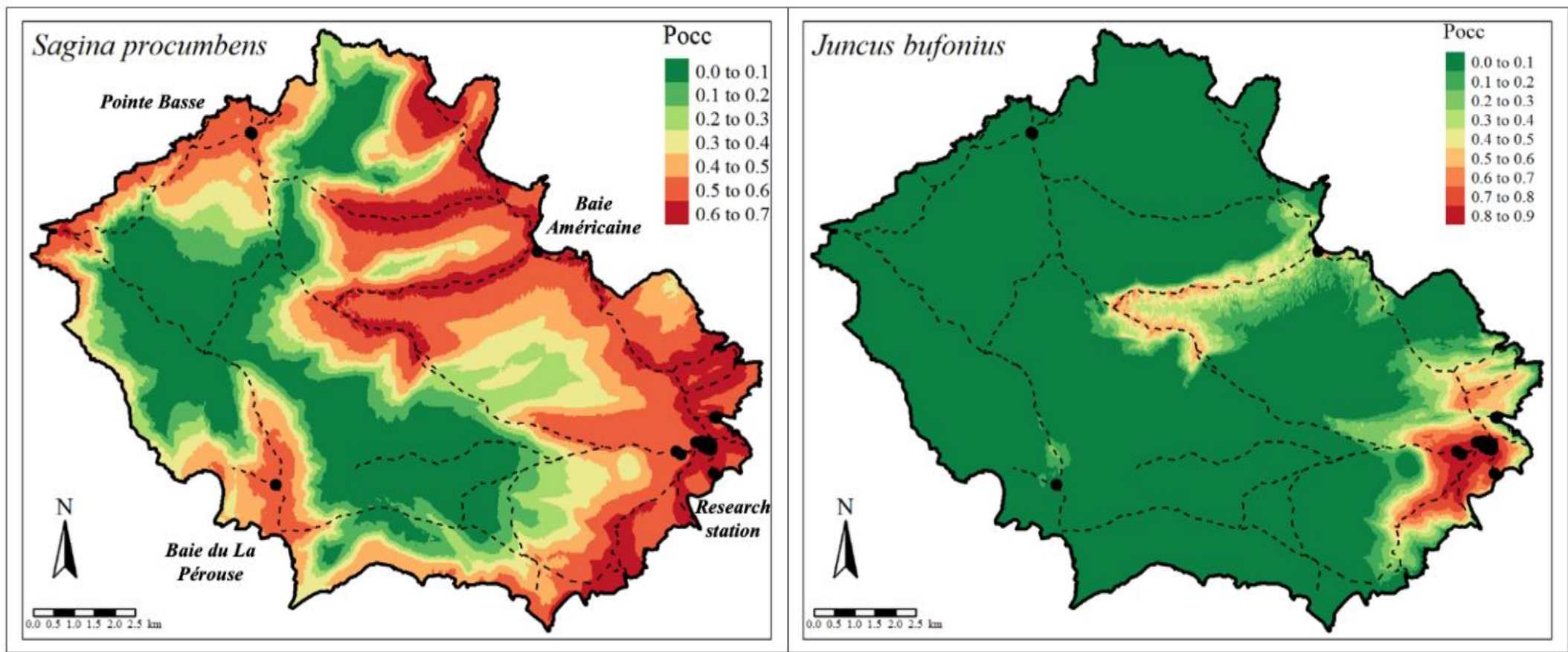

Figure 3 - Predicted occurrence of Sagina procumbens and Juncus bufonius. Pocc: occurrence probability. Dashed lines represent hiking paths, while black dots represent human settlements. Occurrence maps of the other alien species are reported in Appendix S6 (Figure S6.4 and S6.5). 


\subsection{Plant traits and species dependence on propagule pressure}

343 In the preliminary analyses, residence time, life history, vegetative reproduction and plant height 344 showed some relationship with the sum of weights of the human-related variables in the single-SDMs 345 (Appendix S7, Figure S7.6 and S7.8), while seed- and leaf-related traits clearly showed no 346 relationship (Appendix S7, Figure S7.7 and S7.9).

347 Then, the multi-SDM confirmed significant interactions of residence time, life history and plant 348 height with the human-related variables (Appendix S7, Figure S7.10). Residence time and plant 349 height appeared to interact with both human-related variables, while life history seemed to interact 350 only with least cost in determining alien species occurrence. In particular, the effect of human-related 351 variables on alien species occurrence varied with plant height. For instance, the occurrence 352 probability of taller plants sharply decreased when moving away from human facilities, while a 353 weaker and sometimes opposite trend was observed for plant species of shorter statures (Figure 4a,b 354 and Appendix S7, Figure S7.11). In addition, old residents were on average less affected by the 355 human-related variables than new residents (Figure 4a,b and Appendix S7, Figure S7.11a). Finally, 356 perennials appeared to be on average less negatively affected by least cost distance to human 357 settlements than annuals (Figure 4c and Appendix S7, Figure S7.11b,c). 
(a)

Old residents

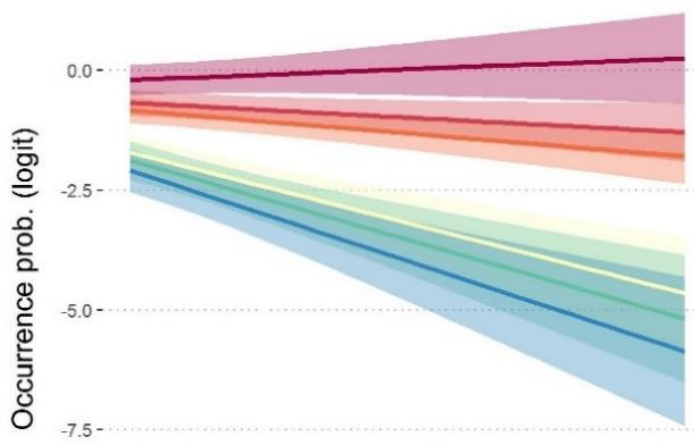

New residents
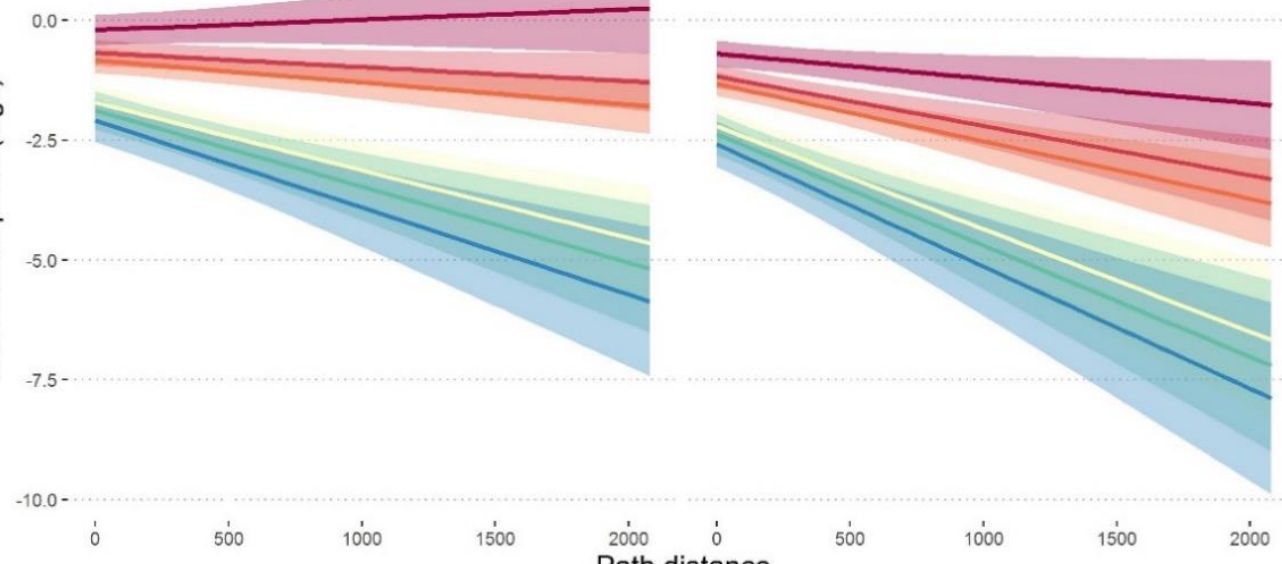

Path distance

(b)
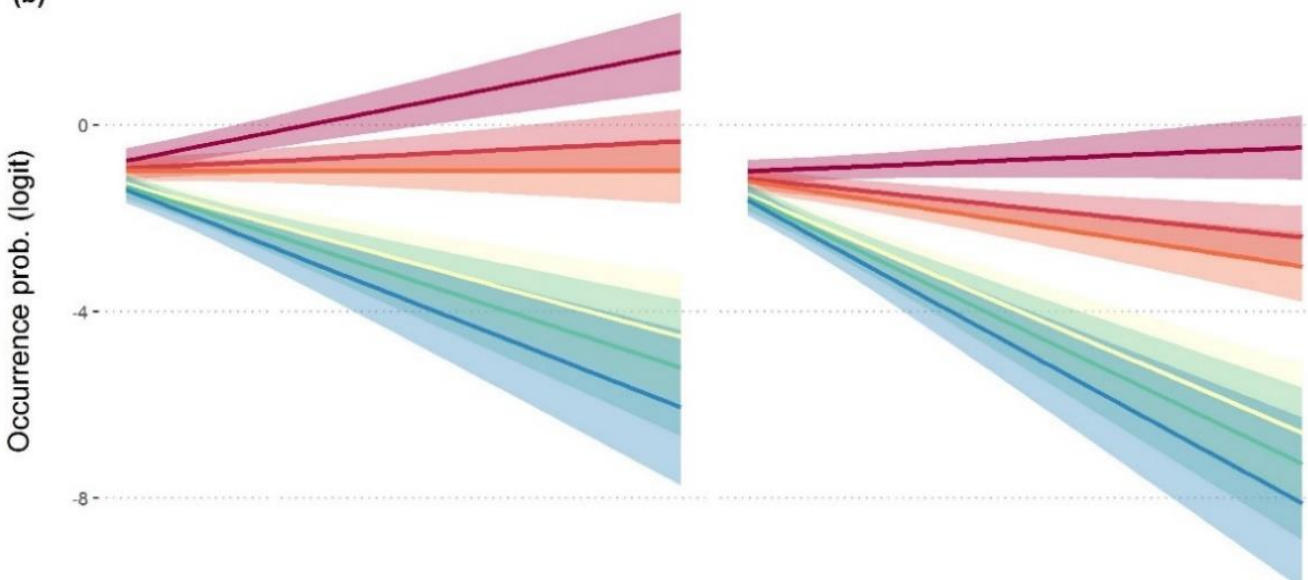

Plant height (mm)

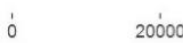

40000

60000

$\dot{0}$
Least cost

20000

40000

60000

(c)
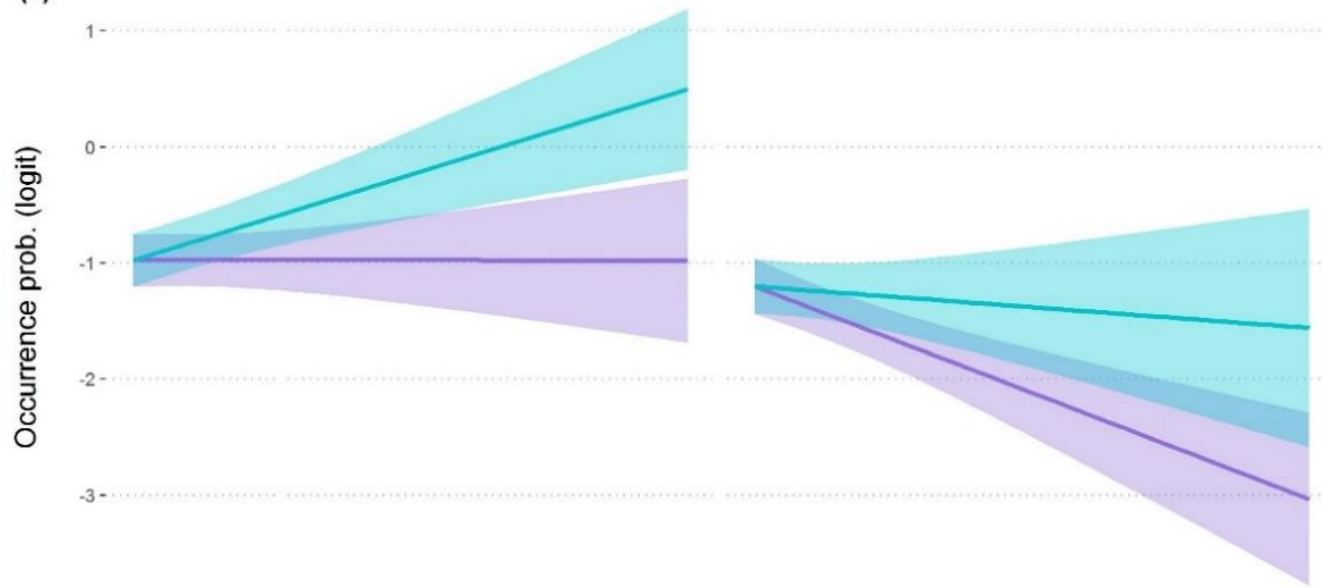

Life history

Annual

Perennial
Plant height (mm)

\section{2}

205

250
26

100

205

225

250

Figure 4 - Effect of the interaction between human-related variables and plant features on alien species occurrence probability (logit scale). Panel (a): effect of the path distance-plant height interaction on old and new resident occurrence probability. Panel (b): effect of the least cost-plant height interaction on old and new (annual) resident occurrence probability. Panel (c): effect of least cost distance to human settlements on annual and perennial (100 mm height) alien species occurrence (for both old and new residents). All plots are reported on a logit scale. 


\section{Discussion}

As hypothesised, both environmental and human-related variables locally affected alien plant species occurrence on Possession Island, though with differences among the studied species. Overall, results confirmed the key role of human-related propagule pressure in favouring alien plant species establishment and spread on sub-Antarctic islands (Frenot et al., 2005; le Roux et al., 2013; Shaw, 2013), though we also observed a significant effect of abiotic conditions. Indeed, climate barriers seemed to prevent alien plant species occurrence in the most environmentally stressful areas of the island, as found in sub(ant)arctic mountain regions by Lembrechts et al. (2016). In particular, our results suggested the existence of two main invasion patterns arising from the species-specific dependence on human-related propagule pressure (Frenot et al., 2005; Shaw, 2013): low-spread species ( $P$. pratensis, $S$. alsine and J. bufonius) strongly relying on human-assisted dispersal along hiking trails and in the vicinity of human settlements; and high-spread species (C. fontanum, P. annua and $S$. procumbens) mostly limited by harsh climatic conditions at high altitudes. Differences in plant invasiveness appeared to be influenced by residence time, life history and plant height, with old residents and perennial short species being more invasive.

Due to their dependence on human-related variables, low-spread species were predicted to occur mainly close to hiking paths and human settlements, pointing to the importance of anthropogenic activities as key drivers of continuous propagule pressure favouring species establishment (Whinam et al., 2005; Pickering \& Mount, 2010). Once introduced through ship-to-shore transport, propagules are then likely to be dispersed on hiking paths through trampling (Whinam et al., 2005). However, the harsher environmental conditions characterizing the west side of Possession Island also limit the occurrence of low-spread species to the east. In particular, the west-east gradient of annual precipitation (Appendix S2, Figure S2.1) clearly overlaps with the low-spread species distribution (Figure 3 and Appendix S6), suggesting that their establishment might be prevented in areas with abundant precipitation. Nevertheless, the precipitation gradient is also connected to human presence, so that in the western side of the island (less inhabited and more preserved) anthropogenic propagule pressure is weaker. In any case, our results evidenced that low-spread species may lack important adaptations to successfully colonise less disturbed areas with limiting abiotic conditions, while remaining relegated to areas of high human presence.

On the contrary, high-spread species appeared weakly (yet positively) influenced by human-related variables, suggesting that, in spite of the undisputed importance of anthropogenic activities in promoting alien plants establishment (Whinam et al., 2005; Huiskes et al., 2014), high-spread species may possess key traits releasing them from direct dependence on anthropogenic propagule pressure. Consequently, these species appeared to be mostly limited by the extreme climatic conditions of the high and cold inner sectors of Possession Island. This result is in line with the findings from Chwedorzewska et al. (2015), who documented the rapid expansion of Poa annua from the Arctowski research base (King George Island) towards wilder areas of the maritime Antarctic Peninsula. Nevertheless, the low predictive performance of high-spread SDMs indicates that the occurrence of these species is poorly explained by the influence of topoclimatic and human-related variables, so that other factors not considered here (e.g. soil properties, plant-soil microbiota interactions, snow cover) may play an important role in driving their distribution at even finer spatial resolutions. In this regard, better performances of the SDMs for high-spread species could have probably been achieved using alien species abundances, which are more informative of the relative habitat suitability than presence-absence data (Howard et al., 2014). 
Critically, although we managed to obtain relatively high-resolution topoclimatic data, it is important to realize that the CHELSA climate for the island (1) might lack the accuracy it has at temperate latitudes, being based on extrapolations from a single weather station, and (2) represents air temperature only, while short plants as those analysed here relate more strongly to soil and nearsurface temperatures (Convey, Coulson, Worland, \& Sjöblom, 2018; Lembrechts et al., 2019). This highlights the need for in-situ soil- and near-surface temperature measurements in remote locations to get more ecologically meaningful climate data (Lembrechts et al., 2020).

Although the small set of analysed alien plant species calls for caution in interpretation, we confirmed here that certain plant traits confer greater invasiveness in sub-Antarctic environments. By relating plant traits to species responses to human-related variables and analysing the effect of their interaction on alien species occurrence, we found evidence that low-stature was a key feature that discriminated invasive from non-invasive alien plant species under the harsh abiotic conditions of Possession Island. Noteworthy, residence time and life history also appeared to affect species invasiveness.

As similarly reported by Mathakutha et al. (2019), we found that high-spread species were of shorter statures than low-spread species. Consistently, we observed a sharper decrease in the occurrence probability of taller plants moving away from both hiking paths and human settlements. As plant height is generally associated with species adaptations to harsh environments (Cornelissen et al., 2003) and, specifically, low-stature has been attributed to frost avoidance mechanisms in high mountains (Márquez, Rada, \& Fariñas, 2006; Ladinig, Hacker, Neuner, \& Wagner, 2013), species of shorter statures may be reasonably favoured in windy and cold sub-Antarctic environments (Mathakutha et al., 2019) and therefore be more easily released of human dependence. Indeed, the importance of functional traits providing tolerance to abiotic stress increases with environmental harshness, even under strong anthropogenic disturbance (Zefferman et al., 2015). Further, our results supported the hypothesis that residence time positively affects invasiveness (Lockwood et al., 2005; Pyšek et al., 2015), though with some exceptions. Generally, old residents (e.g. C. fontanum and $P$. аппиа) were less dependent on human-related propagule pressure and more widely spread than new resident species. Nevertheless, among the old residents, $P$. pratensis was strongly dependent on human-related variables and was still mostly restricted to the original introduction sites. On the other hand, $S$. procumbens, a new resident, has been able to spread extensively and quicker than the other (old residents) high-spread species. However, this might be due to the difference in plant height of the two species: while $P$. pratensis is among the tallest analysed species, $S$. procumbens is the shortest. The multi-SDM showed that perennials were slightly less dependent on human presence than annuals (Figure 4c). Although annuals might benefit from high dispersal abilities (e.g. abundant light seeds) and usually spread quicker and wider (Pertierra et al., 2017), perennials can sustain short growing seasons (Frenot et al., 2001; Shaw, 2013) and potentially colonise harsher environments (Dietz \& Edwards, 2006). In our case, short perennials (e.g. C. fontanum) might be favoured over tall annuals (e.g. J. bufonius) due to the interaction between stress-tolerant traits, such as plant height, and high abiotic tolerance.

Albeit the interaction between vegetative reproduction and human-related variables was not included in the most parsimonious multi-SDM, alien species may still benefit from sexual reproduction, as suggested from the lower importance of human-related variables for the occurrence of alien plants reproducing sexually in the single-SDMs (Appendix S7). As discussed above, the high dispersal potential of sexually reproducing alien species, together with the ability to form rich seed banks (Wódkiewicz et al., 2014), may foster their extensive spread as, for instance, observed for P. annua in the Antarctic Peninsula (Pertierra et al., 2017). Nonetheless, by reproducing vegetatively, perennials might outcompete annuals in maintaining viable and persistent populations during 
unfavourable seasons. Finally, in spite of their acknowledged importance in conferring invasiveness in sub-Antarctic islands (Mathakutha et al., 2019), we found no evidence of the role of seed and leaf traits in affecting species dependence on human-related variables. This is possibly due to the small set of analysed alien species or to the lack of abundance data, which might have prevented the emergence of further functional traits-anthropogenic variables relationships.

Despite some limitations inherent to our dataset (e.g. limited number of species, lack of alien species abundance data) and other typical limitations specific to invasive species distribution modelling (e.g. underestimation of invasion potential, see Jiménez-Valverde et al., 2011), our approach allowed identifying fine-scale drivers of alien plant species distribution, along with the most likely features that favour their spread beyond sources of continuous human-assisted introductions. Combining information on both plant invasiveness and sub-Antarctic islands invasibility, our study provides relevant insights for anticipating future problematic invasions in these remote and unique environments.

\section{Acknowledgements}

We would like to thank Marc Lebouvier (Ing. CNRS) for his suggestions which strongly improved the manuscript. We acknowledge the contribution of Lise Chambrin (Ing. RNN TAF) and all civil volunteers of the Institut Polaire Français Paul-Emile Victor (IPEV) who collected data used in this research. Also, we thank Dr. Matos, Prof. Convey and Prof. Hortal for their helpful suggestions and comments, which allowed strongly improving the first version of the manuscript.

Funding: Project Granted by the French Polar Institute Paul-Emile Victor 'IPEV 136 Subanteco', Institut Universitaire de France (IUF) 'ENVIE', Stratégie d'attractivité durable (SAD) Région Bretagne 'INFLICT'. JJL is funded by the Research Foundation Flanders (FWO, project OZ7828), MC by a Rita Levi-Montalcini grant.

\section{Authors' contribution}

DR, MB, FM and JL conceived the idea; MB analysed the data with FM, MC and JL; MB led the writing of the manuscript. All authors contributed critically to the drafts and gave final approval for publication.

\section{Data availability statement}

Data and R code available on Zenodo: https://doi.org/10.5281/zenodo.4287498

\section{Conflict of interest disclosure}

The authors of this article declare that they have no financial conflict of interest with the content of this article.

\section{References}

Allouche, O., Tsoar, A., \& Kadmon, R. (2006). Assessing the accuracy of species distribution models: prevalence, kappa and the true skill statistic (TSS). Journal of applied ecology, 43(6), 1223-1232.

Barton, K. (2019). MuMIn: Multi-Model Inference. R package version 1.43.6. https://CRAN.Rproject.org/package $=$ MuMIn

Broennimann, O., Di Cola, V., \& Guisan, A. (2018). ecospat: Spatial Ecology Miscellaneous Methods. R package version 3.0. https://CRAN.R-project.org/package=ecospat 
Burnham, K.P. \& Anderson, D.R. (2002) Model Selection and Multimodel Inference: a Practical Information-Theoretic Approach, 2nd edn. Springer-Verlag, New York.

Catford, J.A., Jansson, R., \& Nilsson, C. (2009). Reducing redundancy in invasion ecology by integrating hypotheses into a single theoretical framework. Divers. Distrib., 15(1), 22-40.

Chwedorzewska, K. J., Giełwanowska, I., Olech, M., Molina-Montenegro, M. A., Wódkiewicz, M., \& Galera, H. (2015). Poa annua L. in the maritime Antarctic: an overview. Polar Record, 51(6), 637643.

Convey, P., Coulson, S. J., Worland, M. R., \& Sjöblom, A. (2018). The importance of understanding annual and shorter-term temperature patterns and variation in the surface levels of polar soils for terrestrial biota. Polar Biology, 41(8), 1587-1605.

Convey, P., Key, R.S., \& Key, R.J.D. (2010). The establishment of a new ecological guild of pollinating insects on sub-Antarctic South Georgia. Antarct. Sci., 22(5), 508-512.

Convey, P., \& Lebouvier, M. (2009). Environmental change and human impacts on terrestrial ecosystems of the sub-Antarctic islands between their discovery and the mid-twentieth century. In Papers and proceedings of the royal society of Tasmania (Vol. 143, No. 1, pp. 33-44).

Cornelissen, J.H.C., Lavorel, S., Garnier, E., Diaz, S., Buchmann, N., Gurvich, D.E., ... Pausas, J.G. (2003). A handbook of protocols for standardised and easy measurement of plant functional traits worldwide. Aust. J. Bot., 51(4), 335-380.

Cuba-Díaz, M., Fuentes, E., \& Rondanelli-Reyes, M. (2015). Experimental culture of non-indigenous Juncus bufonius from King George Island, South Shetland Island, Antarctica. 极地研究, 26(1English), 24-29.

Dengler, J. (2016). Phytosociology. International Encyclopedia of Geography: People, the Earth, Environment and Technology: People, the Earth, Environment and Technology, 1-6.

Dietz, H., \& Edwards, P. J. (2006). Recognition that causal processes change during plant invasion helps explain conflicts in evidence. Ecology, 87(6), 1359-1367.

Duffy, G.A., \& Lee, J.R. (2019). Ice-free area expansion compounds the non-native species threat to Antarctic terrestrial biodiversity. Biol. Cons., 232, 253-257.

Duffy, G.A., Coetzee, B.W., Latombe, G., Akerman, A.H., McGeoch, M.A., \& Chown, S.L. (2017). Barriers to globally invasive species are weakening across the Antarctic. Divers. Distrib., 23(9), 982996.

Etten, J.V. (2018). gdistance: Distances and Routes on Geographical Grids. R package version 1.2-2. https://CRAN.R-project.org/package=gdistance

Fotheringham, A.S., \& Rogerson, P.A. (Eds.). (2008). The SAGE handbook of spatial analysis. Sage.

Fox, J., \& Weisberg, S. (2019). An R Companion to Applied Regression (Third). Thousand Oaks CA: Sage. https://socialsciences.mcmaster.ca/jfox/Books/Companion/

Frenot, Y., Chown, S.L., Whinam, J., Selkirk, P.M., Convey, P., Skotnicki, M., \& Bergstrom, D.M. (2005). Biological invasions in the Antarctic: extent, impacts and implications. Biol. Rev., 80(1), 4572. 
Frenot, Y., Gloaguen, J.C., Massé, L., \& Lebouvier, M. (2001). Human activities, ecosystem disturbance and plant invasions in subantarctic Crozet, Kerguelen and Amsterdam Islands. Biol. Cons., 101(1), 33-50.

Greve, M., Mathakutha, R., Steyn, C., \& Chown, S.L. (2017). Terrestrial invasions on sub-Antarctic Marion and Prince Edward Islands. Bothalia-African Biodiversity \& Conservation, 47(2), 1-21.

Guisan, A., Thuiller, W., \& Zimmermann, N.E. (2017). Habitat suitability and distribution models: with applications in $R$. Cambridge University Press.

Gutt, J., Zurell, D., Bracegridle, T., Cheung, W., Clark, M., Convey, P., ... Griffiths, H. (2012). Correlative and dynamic species distribution modelling for ecological predictions in the Antarctic: a cross-disciplinary concept. Polar Res., 31(1), 11091.

Hattab, T., Garzón-López, C.X., Ewald, M., Skowronek, S., Aerts, R., Horen, H., ... Feilhauer, H. (2017). A unified framework to model the potential and realized distributions of invasive species within the invaded range. Divers. Distrib., 23(7), 806-819.

Hijmans, R.J. (2019). raster: Geographic Data Analysis and Modeling. R package version 3.0-2. https://CRAN.R-project.org/package=raster

Howard, C., Stephens, P. A., Pearce-Higgins, J. W., Gregory, R. D., \& Willis, S. G. (2014). Improving species distribution models: the value of data on abundance. Methods Ecol. Evol., 5(6), 506-513.

Hughes, K.A., Convey, P., Pertierra, L.R., Vega, G.C., Aragón, P., \& Olalla-Tárraga, M.Á. (2019). Human-mediated dispersal of terrestrial species between Antarctic biogeographic regions: A preliminary risk assessment. J. Environ. Manage., 232, 73-89.

Hughes, K.A., Pertierra, L.R., Molina-Montenegro, M.A., \& Convey, P. (2015). Biological invasions in terrestrial Antarctica: what is the current status and can we respond?. Biodiversity and Conservation, 24(5), 1031-1055.

Huiskes, A.H., Gremmen, N.J., Bergstrom, D.M., Frenot, Y., Hughes, K.A., Imura, S., ... Ware, C. (2014). Aliens in Antarctica: assessing transfer of plant propagules by human visitors to reduce invasion risk. Biol. Cons., 171, 278-284.

Jiménez-Valverde, A., Peterson, A. T., Soberón, J., Overton, J. M., Aragón, P., \& Lobo, J. M. (2011). Use of niche models in invasive species risk assessments. Biol. invasions, 13(12), 2785-2797.

Karger, D.N., Conrad, O., Böhner, J., Kawohl, T., Kreft, H., Soria-Auza, R.W., ... Kessler, M. (2017). Climatologies at high resolution for the earth's land surface areas. Sci. data, 4, 170122.

Kattge, J., Bönisch, G., Díaz, S., Lavorel, S., Prentice, I.C., Leadley, P., ... Acosta, A.T. (2020). TRY plant trait database-enhanced coverage and open access. Global Change Biol.

Ladinig U, Hacker J, Neuner G, Wagner J (2013) How endangered is sexual reproduction of highmountain plants by summer frosts? Frost resistance, frequency of frost events and risk assessment. Oecologia 171:743-760

Lebouvier, M., Laparie, M., Hulle, M., Marais, A., Cozic, Y., Lalouette, L., ... Renault, D. (2011). The significance of the sub-Antarctic Kerguelen Islands for the assessment of the vulnerability of native communities to climate change, alien insect invasions and plant viruses. Biol. Invasions, 13(5), 1195-1208.

Lembrechts, J. J., Aalto, J., Ashcroft, M. B., De Frenne, P., Kopecký, M., Lenoir, J., ... García, R. A. (2020). SoilTemp: a global database of near-surface temperature. Global Change Biol., 26, 66166629. 
Lembrechts, J.J., Lenoir, J., Roth, N., Hattab, T., Milbau, A., Haider, S., ... Nuñez, M.A. (2019). Comparing temperature data sources for use in species distribution models: From in-situ logging to remote sensing. Global Ecol. Biogeogr., 28(11), 1578-1596.

Lembrechts, J.J., Pauchard, A., Lenoir, J., Nuñez, M.A., Geron, C., Ven, A., ... Milbau, A. (2016). Disturbance is the key to plant invasions in cold environments. PNAS, 113(49), 14061-14066.

Lenoir, J., Hattab, T., \& Pierre, G. (2017). Climatic microrefugia under anthropogenic climate change: implications for species redistribution. Ecography, 40(2), 253-266.

Lenoir, J., Gégout, J.C., Guisan, A., Vittoz, P., Wohlgemuth, T., Zimmermann, N.E., ... Virtanen, R. (2010). Cross-scale analysis of the region effect on vascular plant species diversity in southern and northern European mountain ranges. PLoS One, 5(12).

le Roux, P.C., Ramaswiela, T., Kalwij, J.M., Shaw, J.D., Ryan, P.G., Treasure, A.M., ... Chown, S.L. (2013). Human activities, propagule pressure and alien plants in the sub-Antarctic: Tests of generalities and evidence in support of management. Biol. Cons., 161, 18-27.

Lockwood, J.L., Cassey, P., \& Blackburn, T. (2005). The role of propagule pressure in explaining species invasions. Trends Eco. Evo., 20(5), 223-228.

Márquez, E.J., Rada, F., \& Fariñas, M.R. (2006). Freezing tolerance in grasses along an altitudinal gradient in the Venezuelan Andes. Oecologia, 150(3), 393-397.

Massol, F., David, P., Gerdeaux, D., \& Jarne, P. (2007). The influence of trophic status and largescale climatic change on the structure of fish communities in Perialpine lakes. J. Anim. Ecol., 76(3), 538-551.

Mathakutha, R., Steyn, C., le Roux, P.C., Blom, I.J., Chown, S.L., Daru, B.H., ... Greve, M. (2019). Invasive species differ in key functional traits from native and non-invasive alien plant species. $J$. Veg. Sci., 30(5), 994-1006.

Moser, D., Lenzner, B., Weigelt, P., Dawson, W., Kreft, H., Pergl, J., ... Cassey, P. (2018). Remoteness promotes biological invasions on islands worldwide. PNAS, 115(37), 9270-9275.

Ottaviani, G., Keppel, G., Götzenberger, L., Harrison, S., Opedal, Ø. H., Conti, L., ... Negoita, L. (2020). Linking Plant Functional Ecology to Island Biogeography. Trends Plant Sci.

Pérez-Harguindeguy, N., Diaz, S., Gamier, E., Lavorel, S., Poorter, H., Jaureguiberry, P., ... Urcelay, C. (2013). New handbook for stand-ardised measurement of plant functional traits worldwide. Aust. J. Bot. 61: 167-234.

Pertierra, L.R., Aragón, P., Shaw, J.D., Bergstrom, D.M., Terauds, A., \& Olalla-Tárraga, M.Á. (2017). Global thermal niche models of two European grasses show high invasion risks in Antarctica. Global Change Biol., 23(7), 2863-2873.

Pickering, C., \& Mount, A. (2010). Do tourists disperse weed seed? A global review of unintentional human-mediated terrestrial seed dispersal on clothing, vehicles and horses. Journal of Sustainable Tourism, 18(2), 239-256.

Pyšek, P., Manceur, A.M., Alba, C., McGregor, K.F., Pergl, J., Štajerová, K., ... Lučanová, M. (2015). Naturalization of central European plants in North America: species traits, habitats, propagule pressure, residence time. Ecology, 96(3), 762-774.

Pyšek, P., \& Richardson, D.M. (2008). Traits associated with invasiveness in alien plants: where do we stand?. In Biol. Invasions (pp. 97-125). Springer, Berlin, Heidelberg. 
615 Richardson, D.M., \& Pyšek, P. (2006). Plant invasions: merging the concepts of species invasiveness 616 and community invasibility. Prog. Phys. Geogr., 30(3), 409-431.

617 Shaw, J.D. (2013). Southern Ocean Islands invaded: conserving biodiversity in the world's last 618 wilderness. In Plant Invasions in Protected Areas (pp. 449-470). Springer, Dordrecht.

619 Srivastava, V., Lafond, V., \& Griess, V. C. (2019). Species distribution models (SDM): applications, 620 benefits and challenges in invasive species management. CAB Reviews, 14(020), 1-13. 621 10.1079/PAVSNNR201914020

622 van Kleunen, M., Dawson, W., \& Maurel, N. (2015). Characteristics of successful alien 623 plants. Molecular Ecology, 24(9), 1954-1968.

624 van Kleunen, M., Weber, E., \& Fischer, M. (2010). A meta-analysis of trait differences between 625 invasive and non-invasive plant species. Ecology letters, 13(2), 235-245.

626 Whinam, J., Chilcott, N., \& Bergstrom, D.M. (2005). Subantarctic hitchhikers: expeditioners as 627 vectors for the introduction of alien organisms. Biol. Cons., 121(2), 207-219.

628 Wilson, J.R.U., Richardson, D.M., Rouget, M., Proches, S., Amis, M.A., Henderson, L. ... Thuiller, 629 W. (2007). Residence time and potential range: crucial considerations in modelling plant invasions. 630 Divers. Distrib., 13, 11-22.

631 Wódkiewicz, M., Ziemiański, M., Kwiecień, K., Chwedorzewska, K. J., \& Galera, H. (2014). Spatial 632 structure of the soil seed bank of Poa annua L. - alien species in the Antarctica. Biodiversity and 633 Conservation, 23(6), 1339-1346.

634 Zefferman, E., Stevens, J. T., Charles, G. K., Dunbar-Irwin, M., Emam, T., Fick, S., ... Young, T. P. 635 (2015). Plant communities in harsh sites are less invaded: a summary of observations and proposed 636 explanations. AoB Plants, 7. 


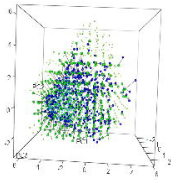




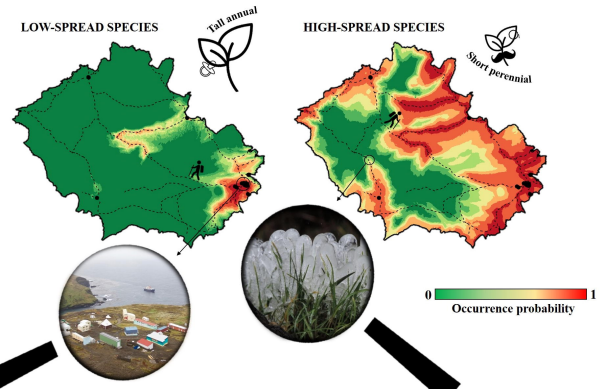

